\title{
7 Table des titres des chapitres du Livre des offices
}

[Prologue du traducteur] (0.1-0.25)

[Prologue de l'auteur] (I.1.1-I.7.2)

[Livre I]

De la division et diffinicion des offices (I.7.3-I.8.2)

Des questions de tracter des offices (I.9.1-I.10.6)

De la proprieté naturelle des hommes (I.11.1-I.14.4)

De quelles offices et vertus vient honnesteté (I.15.1-I.15.6)

De la cognoissance de verité et des vices que on y doit fuir (I.18.1-I.18.9)

De justice et injustice et des genres d'icelles (I.20.1-I.27.3)

En quelles causes on peult delaisser à vanger autrui et en quelles causes on le doit vanger (I.28.1 -I.32.13)

De l'injure malicieuse et calumpnieuse (I.33.1-I.41.9)

De benignité et liberalité (I.42.1-I.60.3)

De force (I.61.1-I.92.6)

De actrempance (I.93.1-I.151.13)

De la comparaison de deux choses honnestes pour savoir si l'une est plus honneste que l'autre (I.152.1-I.161)

Explicit liber primus

[Livre II]

Incipit liber secundus (II.1.1-II.8.6)

De utilité (II.9.1-II.10.5)

De la division des choses utiles et de l'invencion d'icelles (II.11.1-II.51.11)

De liberalité (II.52.1-II.60.10)

De begnificence (II.61.1-II.85.5)

De la maniere de garder santé et peccune (II.86.1-II.87.2)

De la comparaison des choses utiles pour savoir laquelle est la plus utile (II.88.1-II.90.1)

Explicit liber secundus

[Livre III]

Incipit liber tercius (III.1.1-III.6.11)

Note: Pour rappel, une telle table n’apparaît dans aucun des témoins du texte.

Ә Open Access. (c) 2019 Olivier Delsaux, published by De Gruyter. (c) BY-NC-ND This work is licensed under the Creative Commons Attribution-NonCommercial-NoDerivatives 4.0 License.

https://doi.org/10.1515/9783110621365-007 
De la comparacion des choses utiles et honnestes en la vertu de sapience (III.7.1-III.20.8)

De la comparacion de honnesteté et utilité en la vertu de justice (III.21.1III.115.6)

De la comparacion de honnesteté et utilité en la vertu de actrempance (III.116.1III.121.11)] 